\title{
Inezil Penna Marinho: formação de um intelectual da educação física ${ }^{1}$
}

André Dalben*

\begin{abstract}
Resumo: O presente trabalho tem por objetivo compreender os motivos que levaram Inezil Penna Marinho a escolher a educação física como profissão e se afirmar nesta área na década de 1940. Por meio de uma escrita biográfica que se inicia em 1933, seu último ano de estudos no Colégio Pedro II e encerrase em 1945, quando se afirma como importante intelectual da educação física, este artigo resgata principalmente as práticas esportivas nas quais Inezil Penna Marinho se envolveu durante sua juventude, assim como o aporte intelectual em que esteve mergulhado durante esses anos.

Palavras chave: Biografia. História. Educação física: Brasil.
\end{abstract}

\section{Prólogo}

Inezil Penna Marinho (1915 - 1985) é reconhecido como um dos maiores intelectuais da educação física brasileira. Sua extensa produção acadêmica, que no ano de "[...] 1958 já tinha mais de 100 monografias e dezenas de livros publicados" (MELO, 2008, p.180), agregou ao debate acadêmico da educação física brasileira disciplinas como a história e filosofia. Em 1943, publicou a obra que ganharia maior destaque em sua carreira, intitulada "Contribuições para a história da educação física no Brasil”, obra em que reunia, a partir de uma minuciosa e ampla pesquisa documental, datas e fatos que considerava de maior relevância para compor a história da educação física, a partir de fontes como legislação, jornais, revistas, teses, livros e súmulas. Segundo seus escritos, esta obra tinha por objetivo principal a preservação da memória esportiva e da educação física brasileira.

\footnotetext{
${ }^{1}$ Agradeço aos professores Sidney Chalhoub e Carmen Lúcia Soares pelas contribuições a esta pesquisa.

* Doutorando do Programa de Pós-Graduação da Faculdade de Educação da UNICAMP. Mestre em Educação Física pela UNICAMP. Licenciado em Educação Física pela UNICAMP Campinas, SP, Brasil. E-mail: andredalben@yahoo.com.br.
} 
A influência desta obra foi tão grande que chegou a homogeneizar o ensino de história e as abordagens historiográficas da educação física brasileira por muito tempo (CASTELLANI FILHO, 1988). Na década de 1980, entretanto, foi criticada por diversos autores, os quais argumentavam principalmente que o seu estudo historiográfico consistia tão somente de um levantamento de datas, fatos e autoridades, apresentados cronologicamente sem que houvesse análises críticas dos objetos abordados.

Na década de 1990, novos estudos referentes à obra de Inezil Penna Marinho procuraram compreendê-la a partir das características da produção historiográfica do período em que foi escrita, apaziguando assim o tom pejorativo das críticas estabelecidas na década anterior (NASCIMENTO, 1997; FERREIRA NETO, 1999). Estes estudos caracterizaram-na como um belo exemplo da história episódica, por ter realizado um destacável, e inaugural, levantamento de datas, nomes e fatos históricos da educação física brasileira (MELO, 1998). Tais argumentos corroboraram para que a obra continuasse a ser utilizada nos dias atuais como um "catálogo historiográfico" para o levantamento de fontes de pesquisa.

Recentemente o resgate da produção de Inezil Penna Marinho vem ocorrendo a partir da abertura de seu acervo particular. Com o objetivo principal de tornar público suas obras até então desconhecidas, tem-se realizado o levantamento, catalogação e a publicação deste material (GOELLNER, 2005). Novas problematizações quanto à produção acadêmica de Inezil Penna Marinho estão sendo sugeridas a partir de suas obras inéditas (GOELLNER; SILVA, 2009; GOELLNER, et al., 2009), assim como há também o ressurgimento, por meio de escritos biográficos, do interesse nas diferentes facetas de sua vida (MELO, 2008).

É interessante notar que a biografia tem composto lugar de destaque na produção historiográfica atual, uma vez que possibilita a indagação sobre os atos e os pensamentos da vida cotidiana, sobre as dúvidas e incertezas de uma personagem, e principalmente a respeito do caráter fragmentário e dinâmico de uma identidade, dos momentos contraditórios no transcorrer de uma existência (DOSSE, 2009; LEVI, 2000).

Movimento, Porto Alegre, v. 17, n. 01, p. 59-76, janeiro/março de 2011. 
Ao dividir a vida de Inezil Penna Marinho em três momentos - "Estudante e literato", "Atleta e Esportista" e "Educador Físico e Intelectual" - procurei reconstruir algumas das facetas dessa personagem do passado que até o presente mantém-se como um dos grandes nomes da educação física brasileira e ainda exerce fascínio em grande parte dos profissionais de educação física atual.

Esta tarefa não se constitui com o objetivo de destacar virtudes ou vícios desta personagem em questão, mas antes, de nuançar as expectativas historicamente impostas a sua figura de intelectual, de pensá-lo como um homem de seu tempo, constituído de carne, incertezas e incoerências. Neste sentido, três questões principais se impõem neste artigo biográfico: os motivos e os percursos que levaram Inezil Penna Marinho a escolher a educação física como profissão; as trajetórias profissionais e acadêmicas que percorreu para se afirmar enquanto intelectual desta área na década de 1940; os aportes intelectuais e as práticas cotidianas de sua juventude que possibilitaram unir, nesta década em questão, os estudos da história e da filosofia à educação física brasileira. De modo mais amplo percorreremos, orientados pelos atuais estudos da história da educação física, algumas das configurações que práticas corporais como o esporte, as lutas e as ginásticas, assumiram durante as décadas de 1930 e 1940 no Brasil, as quais influenciaram, e foram influenciadas, não apenas por Inezil Penna Marinho como por diversos outros professores de educação física desta época.

Wovimento, Porto Alegre, v. 17, n. 01, p. 59-76, janeiro/março de 2011. 


\section{ESTUDANTE E LITERATO}

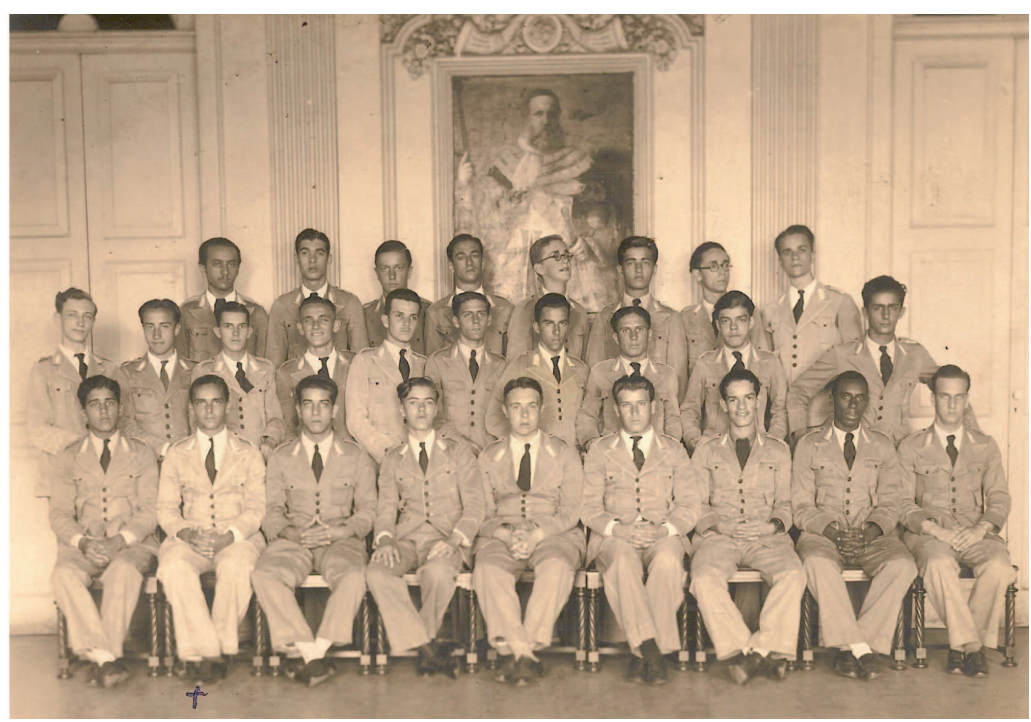

Figura 1: Turma de 1933 do Internato do Colégio Pedro II

Fonte: Centro de Memória do Esporte da Escola de Educação Física da UFRGS. ${ }^{2}$

Soldados da ciência, tendo no livro seu escudo e na inteligência sua arma, os alunos do Colégio Pedro II, conforme o hino comemorativo de seu centenário (em 1937), tinham por missão levar nas mãos o futuro de uma grande e brilhante nação. A fotografia, como instrumento desta nobre missão, registrava seus combatentes em perfeito aprumo. Imortalizado na imagem com as mãos contidas em posição sóbria, corpo alinhado em solene vestuário, Inezil Penna Marinho posicionava-se na primeira fileira. Os vinte e sete alunos, fotografados no quinto e último ano do internato (1933), representavam a promessa de futuros governantes e intelectuais brasileiros.

Em seus momentos livres no colégio, Inezil Penna Marinho sempre procurava pela biblioteca. Aos alunos do $5^{\circ}$ ano era reservado o "[...] privilégio de poder consultá-la livremente, sem horário prédeterminado" (MARINHO, 1985, p.13). Seu encanto pela biblioteca repercutiria por toda a sua vida. Autor de centenas de trabalhos

${ }^{2}$ Disponível em: http://hdl.handle.net/10183/17573. Acesso em: 10 de outubro de 2010.

Movimento, Porto Alegre, v. 17, n. 01, p. 59-76, janeiro/março de 2011. 
acadêmicos também publicou algumas obras literárias, havendo ainda outras diversas não publicadas em seu acervo particular.

Era na biblioteca do Colégio Pedro II que "[...] buscava uma fonte de inspiração para um poema forte" que pretendia escrever em 1933 para o concurso literário da Academia de Ciências e Letras daquele estabelecimento de ensino. Encontrou-a nas gravuras de Albrecht Dürer, "Os Quatro Cavaleiros do Apocalipse". A Guerra, a Fome, a Peste e a Morte tornaram-se as personagens principais de sua composição literária, as quais, vindas do Norte, marchavam em andar despreocupado e avassalador, destruindo de maneira implacável o povo de uma região antes abastada. O poema de caráter épico, intitulado "Tetrálogo dos Cavaleiros do Apocalipse", lhe rendeu o primeiro lugar no concurso e recebeu na ocasião da condecoração a obra "Os Sertões" de Euclides da Cunha. Tal evento e escritos apresentam-se como bastante significativos na vida de nossa personagem que logo adiante escolheria como uma de suas profissões a educação física, a qual, em sua época, era tida como uma importante medida higiênica capaz de apaziguar os diferentes males que assolavam a sociedade, como as epidemias, por meio do fortalecimento o corpo. No entanto, suas contribuições para a área não se ateriam às ciências médicas e biológicas. Suas pesquisas na educação física tomariam como aporte teórico estudos da filosofia, da psicologia e do direito, oriundos de sua vasta formação acadêmica.

Neste mesmo ano de 1933, já tinha um livro de poesias preparado. Chamava-se "Castália", o qual pôde ser publicado, utilizando-se de recursos próprios, somente em 1945. Orgulhoso com o resultado do concurso literário promovido pelo Colégio Pedro II, o jovem Inezil Penna Marinho decidiu aperfeiçoar os conhecimentos da arte poética que lhe haviam sido ministrados por seu pai, o magistrado Idefonso Ayres Marinho: "Lembro-me até de quando tamborilava com os dedos, contando as sílabas de cada verso" (MARINHO, 1979, p.12). De acordo com suas anotações, foi no período de 1933 a 1938, logo após ter concluído os estudos no internato do Colégio Pedro II e de ter sido condecorado no concurso, que mais se dedicou à escrita literária, tendo iniciado treze composições entre poesias, novelas, contos e crônicas.

Wovimento, Porto Alegre, v. 17, n. 01, p. 59-76, janeiro/março de 2011. 
"Castália" anunciava seu fascínio pelo mundo grego, o qual repercutiria em grande parte de seus escritos nas áreas do direito e da educação física, como em sua obra "Os clássicos e a educação física", de 1945 (a). É provável que o seu primeiro contato com a cultura clássica tenha sido proporcionado pela forte formação humanista oferecida pelo tradicional Instituto La-Fayette, onde concluiu seus estudos primários (FERNANDES, 1979, p.249). Durante sua vida visitou por várias vezes a Grécia, e em 1956, quando assumia a cadeira de História da Educação Física na antiga Universidade do Brasil, solicitou a contratação de um tradutor de grego e latim, assim como a aquisição de mapas do mundo antigo, reconhecendo assim uma visão humanista da pesquisa em educação física (MELO, 2008, p.183).

Segundo seus relatos, foi enquanto criava um poema para o livro "Castália" que lhe surgiu a ideia de escrever uma coroa de sonetos ${ }^{3}$ sobre a Grécia. Chegou, na ocasião, a redigir o verso inicial, mas só o concluiu quarenta e cinco anos depois. Publicado com o título de "Oh, Grécia!" demonstra a grande erudição de Inezil Penna Marinho, podendo ser considerada como sua grande homenagem a cultura clássica que tanto lhe fascinou e sobre a qual dissertou em diversas obras acadêmicas.

Entre os escritos literários iniciados em 1933 o conto, "O Homem-Féra" apresenta uma estória particularmente interessante. Com uma narrativa próxima a gêneros literários como "[...] as novelas de aventuras, as aventuras marítimas, os diários de viagem, o romance romântico, o relato científico e a descrição etnográfica" (BITTENCOURT, 2009, p.102), dialoga com os mais diferentes embates estabelecidos entre o civilizado e a natureza bruta.

Com uma ficção que mistura elementos de obras como "Frankestein", de Mary Shelley, "A Ilha do Dr. Moreau" de H. G. Wells e "O Médico e o Monstro" de Robert Louis Stevenson, apenas para citar alguns, "O Homem-Féra" trata a respeito de uma experiência científica mal sucedida, realizada numa ilha da floresta Amazônia,

\footnotetext{
${ }^{3}$ Coroa de sonetos é uma forma poética composta por 14 sonetos, que têm ligação entre si, cujos primeiros e últimos versos são versos de um outro (décimo quinto) soneto, denominado soneto-base, ou soneto-síntese.

Movimento, Porto Alegre, v. 17, n. 01, p. 59-76, janeiro/março de 2011.
} 
que tentou conferir vida a um cadáver por meio do transplante de seu coração pelo de um tigre. O conto de forma alguma expressa a descrença de Inezil Penna Marinho nas ciências biológicas e médicas, principais bases da educação física nos anos em que escreveu esta obra, "[...] é antes o reflexo de um jovem que se tornaria um humanista (para ser mais preciso, diria um humanista secular)." (MELO, 2009, p.137).

Nesse sentido, compreende-se que a formação humanista que empregaria em sua futura profissão de educador físico estava presente desde seus tempos escolares e em sua tradição familiar, herdeira de uma vasta cultura humanística.

\section{AtLeta e esportista}

Quando jovem, compartilhou as horas dedicadas aos estudos clássicos e à escrita literária com outra atividade que em muito lhe entusiasmava e que seria central em sua vida pessoal e profissional: as práticas corporais. Em suas palavras: "Era grande a minha atração pelos desportos; sua prática me proporcionava estado de verdadeira euforia" (MARINHO, 1949, p.3).

Nos tempos do Colégio Pedro II, frequentava regularmente as aulas de ginástica, introduzidas na instituição desde 1841 (CUNHA JUNIOR, 2003). Diversos indícios afirmam que o método ginástico adotado pelo colégio foi o sueco (COELHO, 1995), criado originalmente pelo professor de esgrima da Universidade de Lund, Per-Henrick-Ling (1776-1839). Tal método de trabalho corporal, que se baseava principalmente na fisiologia e anatomia, compreendia especialmente os movimentos de tronco, membros e cabeça, objetivando aperfeiçoar, sobretudo, o aparelho respiratório (MORENO, 2001; SOARES, 1998).

Nos esportes se destacou sempre participando dos Campeonatos Colegiais organizados no Colégio Pedro II. Segundo Meily Assbú Linhales (2006), a presença da prática esportiva nas escolas dessa época não se constituía como regra, mas como exceção, e entre elas incluíam-se principalmente os colégios de tradição anglo-saxônica,

Wovimento, Porto Alegre, v. 17, n. 01, p. 59-76, janeiro/março de 2011. 
os metodistas, prebisterianos e o Pedro II. A esgrima, enquanto componente das lições de ginástica, estava presente nesta instituição de ensino desde 1846 (CUNHA JUNIOR, 2002), assim como os banhos de mar e as caminhadas pela praia, que foram introduzidas em 1885 (GUEDES, 2005) enquanto práticas higiênicas. É difícil precisar ao certo as práticas corporais realizadas por Inezil Penna Marinho durante seus anos escolares, pois são poucas as fontes que as relatam diretamente, no entanto, pode-se afirmar que a nossa personagem estava imersa em todo esse cenário acima descrito.

Em destaque novamente pelo recurso da fotografia, ainda em seu último ano de estudos no Colégio Pedro II, encontra-se entre os demais atletas da equipe esportiva, confirmando assim sua atração pelas práticas corporais. Dessa vez, ao ar livre, como bem condiz com as práticas esportivas do momento, Inezil Penna Marinho e seus colegas apresentam-se em uniforme bem talhado e que permite a exposição de seus físicos atléticos.

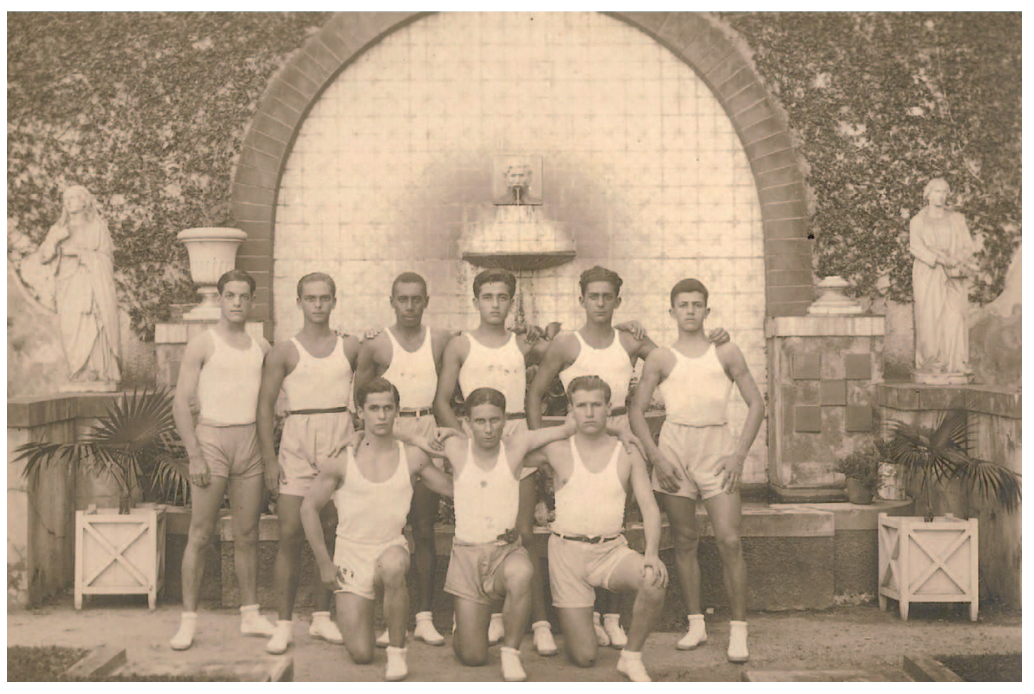

Figura 2: Atletas do $5^{\circ}$ ano do internato do Colégio Pedro II - 1933. Fonte: Centro de Memória do Esporte da Escola de Educação Física da UFRGS. ${ }^{4}$

${ }^{4}$ Disponível em: http://hdl.handle.net/10183/17573. Acesso em: 10 de outubro de 2010.

Movimento, Porto Alegre, v. 17, n. 01, p. 59-76, janeiro/março de 2011. 
Desde o final do século XIX, o Rio de Janeiro anunciava-se uma "cidade sportiva" (MELO, 2001), a qual despertaria cada vez mais a atenção de nossa personagem, que frequentou em sua juventude diversos clubes cariocas, entre eles o Boqueirão do Passeio, no qual se consagrou campeão de polo aquático.

Dentre as práticas corporais as quais se dedicou, teve um especial apreço pelas diversas lutas que frequentavam os rinques cariocas daquela época (SILVA, 2002). Dentre as quais, a capoeira, que, por meio de defensores como Coelho Neto, Annibal Burlamaqui (Zuma) e Agenor Moreira Sampaio (Sinhozinho) iniciou, na década de 1930, um processo de esportivização e de valorização entre as forças armadas e diferentes parcelas da classe média carioca. De modo sucinto, ao ser concebida como uma arte marcial brasileira, pertencente às práticas esportivas, a capoeira legitimar-se-ia perante a sociedade, destituindo-se do caráter pejorativo que a associava até então à vadiagem, motivo pelo qual sempre frequentou o discurso judiciário. (PIRES, 2001; 1996).

A legitimação da capoeira entre as forças armadas conquistou especial promoção quando passou a integrar o quadro de exercícios de preparação corporal dos oficiais do centro de treinamento da Polícia Especial do Governo de Getúlio Vargas, divisão esta a qual Inezil Penna Marinho viria a integrar aos 22 anos (SILVA, 2002, p.133; FARIA apud CASTELLANI FILHO, 1988, p.138). Formada em 1932 por cinquenta homens da polícia civil, cinquenta da militar e cem atletas selecionados em diversos clubes esportivos, a Polícia Especial foi responsável pela repressão aos indivíduos e instituições contrários ao regime centralizador imposto pelo governo de Getúlio Vargas. Sinhozinho, que se dedicou tanto a formação dos policiais do regime varguista, quanto de discípulos na arte da capoeira praticada nos rinques, defendia esta luta como a "verdadeira ginástica nacional, o esporte genuinamente brasileiro", que deveria ser orientada por uma sistematização própria e ser ensinada em clubes, academias e centros de treinamento oficiais (PIRES, 2001).

Seguindo os passos de seu mestre de capoeira, Inezil Penna Marinho publicaria em 1945 (b) o livro "Subsídios para o estudo da

Movimento, Porto Alegre, v. 17, n. 01, p. 59-76, janeiro/março de 2011. 
metodologia do treinamento da capoeiragem", no qual efetivamente sistematizou a capoeira segundo os parâmetros científico militares da educação física, afirmando-a como símbolo étnico representativo da cultura nacional (SILVA, 2002; PIRES, 2001). Esta obra, considerada um dos marcos de sua trajetória intelectual, foi premiada pela Divisão de Educação Física (DEF) do Ministério da Educação e da Saúde, órgão criado em 1937 pelo governo Vargas com o objetivo de estruturar uma organização única para a educação física em todo o Brasil.

A prática de diferentes modalidades de lutas também lhe rendeu a medalha de campeão de luta livre pelo Clube de Regadas do Flamengo. De fato, durante a juventude, consagrou-se campeão em diversas modalidades esportivas, tendo constituído um exímio quadro de troféus e medalhas, no entanto, seu nome seria reconhecido na educação física brasileira principalmente por seus feitos intelectuais, que tiveram início logo após concluir seus estudos superiores de educação física.

\section{PROFESSOR DE EDUCAÇÃo FísicA E INTELECTUAL}

Da união entre duas paixões adquiridas ainda em sua juventude, os livros e as práticas corporais, Inezil Penna Marinho comporia uma destacada carreira na educação física brasileira, no entanto, iniciou seus estudos na Faculdade de Direito da Universidade do Brasil, seguindo assim a herança de seu pai, o cônsul Ildefonso Ayres Marinho. Segundo Amarílio Ferreira Neto $(1999$, p. 216) "[...] ainda jovem, viveu o conflito de ter que estudar Direito na Universidade do Brasil, quando sua grande paixão era o esporte".

Aconselhado por dois colegas do Colégio Pedro II, Luiz Inneco e Archimedes Vargas da Costa Filho, que haviam se formado na Escola de Educação Física do Exército, decide em 1938 conciliar os estudos de direito com o curso de instrutor de educação física na escola militar (MARINHO, 1949).

Wovimento, Porto Alegre, v. 17, n. 01, p. 59-76, janeiro/março de 2011. 
Acostumado com a rotina universitária da Faculdade de Direito, estranhou o rigor militar e a rotina do novo curso que iniciava. Em suas palavras: "Um ano duro. Verdadeiramente duro, não somente sob o ponto de vista de esforço físico como também intelectual. Muitas disciplinas, sabatinas constantes, "carro de fogo" no meio do curso, provas parciais e finalmente o fantasma dos exames finais" (MARINHO, 1949, p. 3). Suas atividades de estudante da EsEFEx abarcavam diversas disciplinas, teóricas e práticas, entre as quais os esportes terrestres e aquáticos e a ginástica.

Neste ponto em específico, do ensino da ginástica, é importante destacar que Inezil Penna Marinho participou de modo ativo nos debates acadêmicos em torno da escolha do melhor método de ginástica a ser empregado no Brasil. Em 1944, quando lançado o "Concurso de Contribuições para o Método Nacional de Educação Física" a proposta vencedora foi a sua, cujas bases se assentavam principalmente em disciplinas como a biologia, sociologia, psicologia, história e filosofia. Tal método nacional nunca foi desenvolvido por completo e adotado efetivamente, no entanto, podemos afirmar que iniciativa de Marinho, reconhecida pela premiação que conquistou, mais uma vez o auxiliaria a alavancar sua carreira neste período histórico, assim como a consolidar propostas referentes à educação física que estivessem em consonância com o governo varguista.

A extenuante rotina de estudos da EsEFEx, aliada às disciplinas e deveres estudantis da Faculdade de Direito, o obrigaram a ter que escolher entre um dos dois cursos. Optou por se dedicar exclusivamente à educação física, interrompendo momentaneamente seus estudos na Faculdade de Direito. "Era impossível realizar os dois simultaneamente, como havia a principio pretendido" (MARINHO, 1949, p. 3).

Movimento, Porto Alegre, v. 17, n. 01, p. 59-76, janeiro/março de 2011. 
Em dezembro de 1938 obteve o título de Instrutor de Educação Física pela EsEFEx e no ano seguinte foi aprovado para o cargo de subassistente técnico na Divisão de Educação Física. É interessante notar que a EsEFEx e a Divisão de Educação Física mantiveram diversas interlocuções nos anos do governo de Getúlio Vargas (MELO, 1996; FERREIRA NETO, 1999), sendo Inezil Penna Marinho um dos atores que estabeleceram relações com ambas. Em 1941, conquistou o cargo de chefe da Secção Pedagógica da Divisão de Educação Física, mesmo ano em que ingressou como aluno no curso de técnico desportivo na Escola Nacional de Educação Física e Desportos (ENEFD), escola-modelo criada em 1939 na Universidade do Brasil com o auxílio da própria Divisão em que trabalhava.

Enquanto aluno deste curso modelo de educação física não deixou de praticar sua grande paixão, obtendo, no Campeonato Universitário, a primeira colocação na modalidade esportiva do polo aquático e o segundo lugar na de voleibol. Seguindo os passos de seu ídolo e colega, Sylvio de Magalhães Padilha, conquistou diversas medalhas no atletismo, "[...] chegando mesmo a ser recordista universitário nos $800 \mathrm{~m}, 1500 \mathrm{~m}, 3000 \mathrm{~m}$ e 4 x 400m" (MELO, 2008, p.180).

A década de 1940 representou para nossa personagem o momento em que obteve seus maiores destaques na educação física brasileira. Foi neste período que se consolidou enquanto profissional de renome, atuando em um órgão governamental de grande proeminência para a ditadura do Estado Novo. Ministrou inúmeras palestras e cursos, ganhou diversos concursos de trabalhos, sentenças ou cartazes patrocinados pela própria Divisão de Educação Física, e publicou grande parte de seus estudos na área, em especial aquele que ganharia maior destaque em sua carreira, "Contribuições para a história da educação física no Brasil", em que teve as condições favoráveis para pesquisar em diferentes arquivos e bibliotecas brasileiras.

Movimento, Porto Alegre, v. 17, n. 01, p. 59-76, janeiro/março de 2011. 
Nesse sentido, é possível afirmar que foi a partir de 1939, quando ingressou na Divisão de Educação Física, que iniciou sua trajetória intelectual, a qual seria bastante beneficiada pelas relações estabelecidas entre a educação física e o governo militar de Getúlio Vargas, relações estas que ele próprio ajudou a formular. Desse modo, podemos compreender que o contato que manteve com os militares auxiliaram-no a alavancar sua carreira na educação física, principalmente durante o Estado Novo, oferecendo-lhe, se não as melhores condições de trabalho, ao menos o período histórico em que a educação física ganharia grande relevância política, em que se instituíram estruturas administrativas diretamente ligadas ao governo militar imposto.

Segundo Ferreira Neto (1999, p.217), a produção intelectual de Inezil Penna Marinho na educação física brasileira torna-se expressiva principalmente na década de 1940, uma vez que na década seguinte, os seus " [...] textos tendem a repetir ideias e assuntos, além de, com frequência, representarem simplesmente republicações". Concomitantemente, sua produção acadêmica na área do direito, curso então finalizado em 1943, aumenta no decorrer dos anos de 1950.

Por volta de 1960, quando se muda para Brasília assumindo cargos jurídicos, deixaria de ter a educação física como atividade central de trabalho. Essa oportunidade de trabalho em Brasília não teria ocorrido porque na época ele era "[...] um importante nome na área de Educação Física, mas por ter quinze anos de atuação como advogado e pertencer ao clã dos Penna Marinho" (FERREIRANETO, 1999, p.217), composto principalmente por seu pai, cônsul, e seu irmão, embaixador do Brasil nos Estados Unidos na década de 1960.

Movimento, Porto Alegre, v. 17, n. 01, p. 59-76, janeiro/março de 2011. 


\title{
5 EPÍLOGO
}

No final da década de 1940, Inezil Penna Marinho fez um balanço de sua vida profissional na Revista Brasileira de Educação Física e expõe as suas opções profissionais adotadas até então da seguinte maneira:

\begin{abstract}
Havendo reiniciado meu curso de direito, termineio em 1943, a advogacia me atraia bastante, mas as raízes que a E.E.F.E havia lançado em meu espírito eram tão profundas que faziam minhas ideias e minhas atividades convergirem exclusivamente para a Educação Física, à qual eu me dedicava cada vez mais. Não poucas vezes pensei em mudar o rumo de minha vida pois o meu cargo de técnico de educação e a minha qualidade de advogado me ofereciam tentadoras oportunidades. E não consigo explicar nem a mim mesmo, as profundas razões que me determinaram continuar ligado à causa da Educação Física (MARINHO, 1949, p. 3)
\end{abstract}

Partindo do pressuposto de que Inezil Penna Marinho fora um entusiasta dos esportes e das práticas corporais desde seus tempos de juventude, torna-se compreensível porque a educação física lhe surgiu como um possível campo de trabalho. Os esportes, assim como as lutas, sempre o acompanharam quando jovem. Entretanto sua formação humanista, advinda dos colégios selecionados por seus pais para cursar os ensinos primários e secundários, assim como a tradição de magistrados de sua família, lhe propuseram outra formação, na área do Direito $^{5}$. Sua inclinação para as humanidades pode ser percebida antes mesmo de iniciar sua graduação na Faculdade de Direito, por meio dos diversos escritos literários que compôs durante a juventude.

O que poderia parecer um impasse na trajetória de nossa personagem conferiu um suporte bastante inovador para suas pesquisas acadêmicas na educação física, pois lhe permitiu

${ }^{5}$ Também se formou nos cursos de psicologia e filosofia oferecidos pela Universidade do Brasil. Em 1941 e 1958, respectivamente.

Movimento, Porto Alegre, v. 17, n. 01, p. 59-76, janeiro/março de 2011. 
analisar os esportes, as ginásticas e a educação física a partir das ciências humanas. Nesse sentido, o caráter inovador de seus estudos foi possível exatamente por reunir durante a sua vida, mais precisamente durante sua formação escolar e os anos de juventude, condições para se dedicar tanto a prática dos esportes quanto aos estudos literários e clássicos, campos que poderiam lhe surgir como opostos, ou incongruentes, acrescentaram à sua carreira o suporte teórico para se destacar em sua atuação profissional.

Os debates nos quais se inseriu intelectualmente, defendendo a capoeira nos parâmetros da educação física de sua época, criando um método brasileiro de ginástica, entre outros, fizeram emergir disputas de poderes nos quais Inezil Penna Marinho, na maioria das vezes, se encontrava no pólo mais forte. Ao escolher como ponto de partida para sua carreira profissional a EsEFEx e ingressar na Divisão de Educação Física em 1939, encontrou o suporte necessário para se destacar profissionalmente, uma vez que seus trabalhos encontravam-se em consonância com as propostas do governo varguista para a educação física brasileira.

Em curto espaço de tempo, Inezil Penna Marinho conquistou grande notoriedade na área. Ganhou diferentes concursos e publicou diversos estudos. Em sua obra de maior repercussão não procurou unicamente contribuir para a construção de uma história da educação física no Brasil. Intentou, sobretudo, conferir sentido e significado para as práticas corporais que apaixonadamente se dedicou na juventude.

Movimento, Porto Alegre, v. 17, n. 01, p. 59-76, janeiro/março de 2011. 
Inezil Penna Marinho: formación de un intelectual de la educación física

Resumen: El presente trabajo tiene como objetivo comprender las razones que ha llevado Inezil Penna Marinho a elegir la educación física como profesión y las formas en que se ha impulsado, en este ámbito, como un gran erudito en el inicio de 1940. Através de un escrito biográfico, que comienza en 1933, su último año de estudios en el Colégio Pedro II, y termina en 1945, cuando se afirma como un importante intelectual de la educación física, este artículo intenta rescatar los deportes que Inezil Penna Marinho ha practicado en su juventud, así como el universo intelectual en que ha estado inmerso en esos años.

Palabras clave: Biografía. História. Educación física: Brasil.

\section{REFERÊNCIAS}

BITTENCOURT, Rita Lenira de Freitas. Visita ao laboratório do grande cientista moderno, Dr. Hildebrando Martins, criador do homem-féra. In: GOELLNER, Silvana V. (Org.); SILVA, André Luiz Santos e (Org.). Recônditos da Memória: o acervo pessoal de Inezil Penna Marinho. 1. ed. Porto Alegre: Gênese, 2009.

CASTELLANI FILHO, Lino. A educação física no Brasil: a história que não se conta. Campinas: Papirus, 1988.

COELHO, Agnaldo Quintela. História oral: lembranças e reconstrução da educação física no Colégio Pedro II - 1930 a 1937. Dissertação (Mestrado em Educação Física), UFG, Rio de Janeiro, 1995.

CUNHA JUNIOR, Carlos Fernando Ferreira da. Os exercícios gymnasticos no Im-

Movimento, Porto Alegre, v. 17, n. 01, p. 59-76, janeiro/março de 2011. 
perial Collegio de Pedro Segundo (1841-1870). Revista brasileira de ciências do esporte, Campinas, v. 25, n. 1, p. 69-81, set. 2003.

CUNHA JUNIOR, Carlos Fernando Ferreira da. Cultura escolar e formação da boa sociedade: uma história do Imperial Collegio de Pedro Segundo. Tese (Doutorado em Educação), UFMG, Belo Horizonte, 2002.

DOSSE, François. O desafio biográfico: escrever uma vida. São Paulo: EDUSP, 2009.

FERNANDES, Aparício. (Org.). Anuário de poetas do Brasil. Rio de Janeiro: Folha Carioca Editora, 1979. v. 4.

FERREIRA NETO, Amarílio. A pedagogia no exército e na escola: a Educação Física brasileira (1880-1950). Tese (Doutorado em Educação), Piracicaba: Universidade Metodista de Piracicaba, 1999.

GOELLNER, Silvana Vilodre; SILVA, André Luiz Santos e (Org.). Recônditos da memória: o acervo pessoal de Inezil Penna Marinho. 1. ed. Porto Alegre: Gênese, 2009.

GOELLNER, Silvana Vilodre. ; SILVA, André Luiz Santos e; OLIVEIRA, Carolina C.; SILVEIRA, L. S.; GONCALVES, Thayanne. R.; MATTOS, Leila Carneiro. A obra de Inezil Penna Marinho e suas repercussões para a estruturação da educação física no Brasil. In: CONGRESSO BRASILEIRO DE CIÊNCIAS DO ESPORTE, 16. e CONGRESSO INTERNACIONAL DE CIÊNCIAS DO ESPORTE, 3. Salvador: CBCE, 2009. Anais ... Goiânia: CBCE, 2009.

GOELLNER, Silvana Vilodre. (Org.). Inezil Penna Marinho: coletânea de textos. Porto Alegre: Universidade Federal do Rio Grande do Sul e Colégio Brasileiro de Ciências do Esporte, 2005.

GUEDES, Claudia. Escola de Educação Física e Esportes da USP. In: COSTA, Lamartine Pereira da. (Org.). Atlas do esporte no Brasil, Rio de Janeiro: Shape, 2005.

LEVI, Giovanni. Usos da biografia. In: AMADO, Janaína; FERRERA, Marieta de Moraes, (orgs.). Usos e abusos da história oral. 3 ed. Rio de Janeiro: Editora FGV, 2000.

LINHALES, Meily Assbú, A escola, o esporte e a "energização do caráter": projetos culturais em circulação na Associação Brasileira de Educação (1925-1935). Tese (Doutorado em Educação), UFMG, Belo Horizonte, 2006.

MARINHO, Inezil Penna. Tetrálogo dos cavaleiros do apocalipse. Brasília: Gráfica Brasiliana, 1985.

MARINHO, Inezil Penna. Oh, Grécia! Brasília: Rio de Janeiro: Tipografia Baptista de Souza \& Cia, 1979.

MARINHO, Inezil Penna. Alguns anos depois... Revista brasileira de educação física, Rio de Janeiro, v.6, n.59, p.3, fev., 1949.

MARINHO, Inezil Penna. Os clássicos e a educação física. Rio de Janeiro: Editora Educação, 1945a.

Wovimento, Porto Alegre, v. 17, n. 01, p. 59-76, janeiro/março de 2011. 
MARINHO, Inezil Penna. Subsídios para o estudo da metodologia do treinamento da capoeiragem. Rio de Janeiro: Imprensa Nacional, 1945b.

MARINHO, Inezil Penna. Contribuições para a história da educação física e dos desportos no Brasil. Rio de Janeiro: Imprensa Nacional, 1943.

MELO, Victor Andrade de. Inezil Penna Marinho: cientista, filósofo, literato. In: GOELLNER, Silvana Vilodre; SILVA, André Luiz Santos e (Org.). Recônditos da memória: o acervo pessoal de Inezil Penna Marinho. 1. ed. Porto Alegre: Gênese, 2009.

MELO, Victor Andrade de. Inezil Penna Marinho e a Escola de Educação Física e Desportos / UFRJ. Arquivos em movimento, Rio de Janeiro, v.4, n.2, p.179-188, Jul./Dez, 2008.

MELO, Victor Andrade de. Cidade sportiva: primórdios do esporte no Rio de Janeiro. Rio de Janeiro: Relume-Dumará, 2001.

MELO, Victor Andrade de. Inezil Penna Marinho: notas biográficas. In: FERREIRA NETO, Amarílio (Org.). Pesquisa histórica na educação física. , Aracruz: Editora da Faculdade de Ciências Humanas de Aracruz, 1998. v.3.

MELO, Victor Andrade de. Escola Nacional de Educação Física e Desportos: uma possível história. Dissertação (Mestrado em Educação Física), UNICAMP, Campinas, 1996

MORENO, Andrea. Corpo e ginástica num Rio de Janeiro: mosaico de imagens e textos. Tese (Doutorado em Educação), UNICAMP, Campinas, 2001.

NASCIMENTO, Célia Carvalho do. Inezil Penna Marinho: o tempo de uma história. Dissertação (Mestrado em História e Filosofia da Educação), São Paulo: Pontifícia Universidade Católica, 1997.

PIRES, Antônio Liberac Cardoso Simões. Movimentos da cultura afro-brasileira: a formação histórica da capoeira contemporânea - 1890 - 1950. Tese (Doutorado em História), UNICAMP, Campinas, 2001.

PIRES, Antônio Liberac Cardoso Simões. A capoeira no jogo das cores. Dissertação (Mestrado em História), UNICAMP, Campinas, 1996.

SILVA, Paula Cristina da Costa. A educação física na roda de capoeira... entre a tradição e a globalização. Dissertação (Mestrado em Educação Física), UNICAMP, Campinas, 2002.

SOARES, Carmen Lúcia. Imagens da educação no corpo: estudo a partir da ginástica francesa no século XIX. Campinas: Autores Associados, 1998.

Financiamento da pesquisa: FAPESP

Recebido em: 28-10-2010

Aprovado em: 17-12-2010

Movimento, Porto Alegre, v. 17, n. 01, p. 59-76, janeiro/março de 2011. 